\title{
Mobile Identities and the Socio-spatial Relations of Air Travel
}

\section{Monika Codourey1}

\section{Introduction}

This paper results from the field research investigating border conditions and their socio-spatial implications at the Frankfurt Main Airport. The field research was done at Frankfurt Main Airport, and it is largely based on interviews with border control officials (BGS and ZOLL), Fraport AG, Lufthansa and Caritas employees. The results of the research were the point of departure for the creation of maps of the diverse transit conditions of air travellers and served as the basis for production of a video devoted to the subject "Data Record of Mobile Identities" media installation. The project was initiated in co-operation with Bauhaus Dessau Foundation in Germany and it is a collaboration with Bettina Boknecht.

\section{From “Kinetic Eites" to "Frequent Fiers"}

In these times of constant mobility, which have been strongly influenced by global economic transformation, metropolises are becoming intersections of transit and the migration of goods, capital, services, cultures, knowledge and especially people. New concepts of urbanity with translational range are emerging. Moreover, the relationship between geographic and social space is shifting. Social realities with specific qualities are appearing beyond traditional descriptions of locality, implying new socio-spatial correlation between the local and the global. Martin Albrow (1997) describes these emerging sozioscapes as "formation of coexisting social spheres, coeval and overlapping in space, but with fundamentally different horizons and time-spans.”

International airports are examples of these emerging transnational spaces. Today many global corporations take advantage of marketing, labour and other cost savings measures by setting up their node-offices all over the world. This practice requires that corporate representatives travel regularly between various locations of a corporate empire. Mark Gottdiener (2001) wrote: "Many jobs are less dependent now on any one location than the use of many locations woven together as spaces for work using laptop, the cellular phone, the internet, or the fax. This mode of de-

\footnotetext{
1 Independent Architect and PhD Research Fellow, Zurich Node of the Planetary Collegium (University of Plymouth) and Institute of Cultural Studies, University of Applied Arts, Zurich, Switzerland. mailto:inom@inom.info website: http://monika.codourey.info/
} 
territorialization involves a progressively greater population and results in a redefinition of home, place, space and local community.”

The nomadic lifestyle is increasingly connected to plane trips and inter- or even transnational activities. It is not only characteristic highly mobile and affluent "Kinetic Elites" (Sloterdijk, 1988) anymore. Today almost all travellers are frequent fliers, and are using air transport the way people in the past used cars and trains for business and leisure.

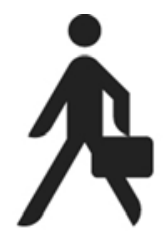

EVENT TOURIST

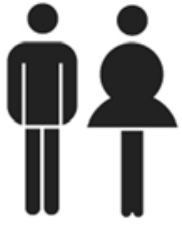

PACKAGE TOURIST

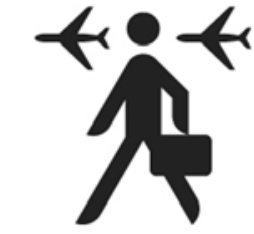

TRANSNATIONAL TRAVELER

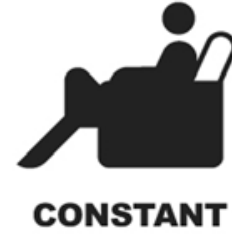

TRAVELER

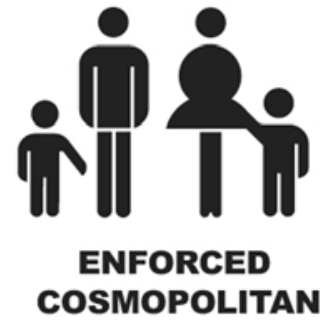

Figure 1: Air Travel Elites: Classification of Frequent Fliers (M. Codourey, Graphic, 2005)

The growing variability of attractive flight offers allow event tourists who are prepared to face cultural shock travelling with inexpensive flights to distant location of around the world. The travel industry offers also endless opportunities to use western level of comfort franchise facilities in exotic places for those who prefer to avoid cultural shock, the package tourists. Also the traditional concepts of migration are being replaced by much more complex and dynamic mobility patterns of a transnational lifestyle. The new migrants, so called transnational travellers, often act as frequently flying agents between country of origins and new domicile. The less desirable group of flying elites are displaced persons, refugees or emigrants, the enforced cosmopolitans, who can afford pay a high price for the flight ticket (often their lifetime savings) in order to escape their miserable life circumstances.

\section{The Aiport Hub: Aesthetics of Soc io-Spatial Mobility}

The Airport Hubs, for example the Frankfurt International Airport are concentrations of local and global flows of information, people and goods in the world-system. They act as a conduit from one physical location in the world to another and can be understood as compressors of space and time. The airport plays an important role in increasing cross-border circulation of frequently flying elites. The airport hubs are transnational spaces inhabited by a mass of people travelling between nodes of global network. The air travel is becoming increasingly inconvenient. Flights are often delayed, overbooked or cancelled. Crowded planes, cramped seating, poor meals and cabin service as well as the sheer boredom resulting from being stranded at terminals for hours are common to the point of cliché.

Different mobility patterns of varying relevance circulate in the airport's structure, and are distributed within airport architecture according to the typology of various levels of comfort and aesthetics. Growing business mobility has led to a segregation within business travellers according to miles spend in the air. For example, the division of lounges into Business, Senator, HON and First Class by Lufthansa exemplifies new strategies, priorities and standards in air travel based on flying status. These Lounges not only offer different level of comfort but as well 
various aesthetic. For example, Lufthansa is setting new international standard for their "premium travellers," who spend the most time in the air and generate $80 \%$ the airlines' profit. Since December 2005, Lufthansa offers for "preferred customers" a luxuriously styled separate HON/First Class terminal. To ensure the most comfortable and smooth travel possible for their top clients, Lufthansa offers its services already on the ground in sophisticated architectural surrounding. The new dimension of travels with exclusive services and privileges includes parking a car to check-in, eased security control and customs, an exclusive ambience with gourmet catering, private rooms for work and refreshment, personal attention, direct limousine transfer to the plane and even concierge services.

For those who do not participate in any airline bonus program, pay-per-use Lounges such as "Europe City Club" or "Priority Club" offer exclusive airport space and services paid on hourly basis.
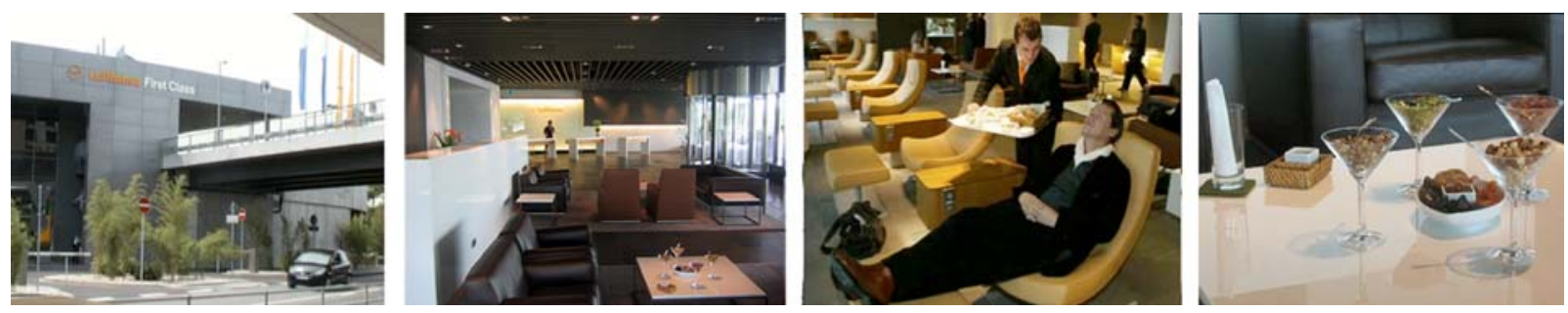

Figure 2: Luxurious design of Lufthansa First Class Terminal: Terminal Build ing, Check-In Area, Waiting Area, Served Snacks (M. Codourey/ B. Boknecht, 2005, Photo-collage)

Growing airline competition and has led to budget optimization of the economy class. For example, cheaper tickets and lowering standards of service or the even opening of low-cost Frankfurt Hahn Airport located $150 \mathrm{~km}$ away from Frankfurt City and linked by bus services with Frankfurt International Airport. Frankfurt-Hahn, a former US military base from the 50-ties, became the first German low cost airport to attain 24-hour operating license. Within only 10 years Frankfurt-Hahn became 10th largest international airport in Germany providing services to all kind of travellers - including cost conscious business people- from whole world.
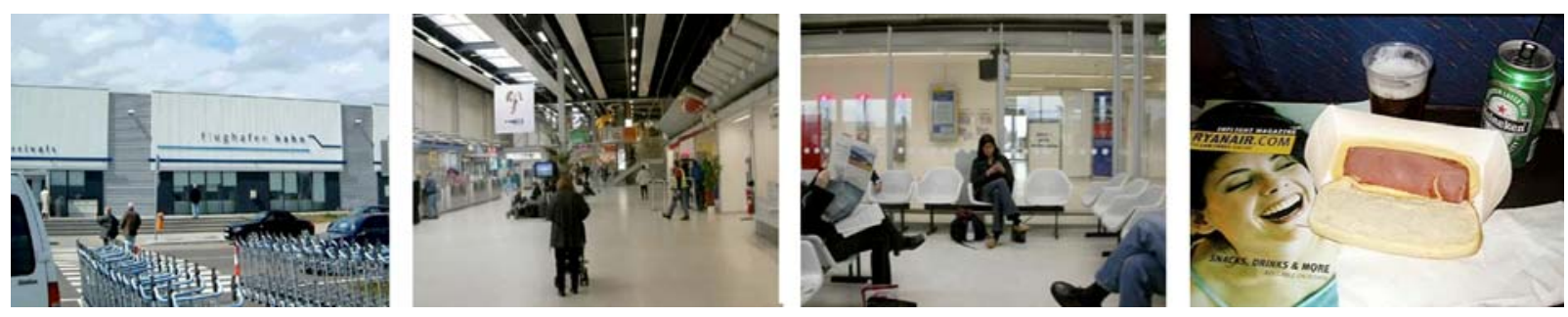

Figure 3: Reduced and price conscious a esthetics of Frankfurt-Ha hn: Terminal Building, Interior, Waiting Room, Aiplane Meal (M. Codourey/Bettina Boknecht, 2005, Photo collage)

Displaced persons, refugees and immigrants are the unwanted part of the spatial segregation regime, within the airport space, in-between nation states. Shortly after the implementation of the 
"Airport Procedure" 2 the new special purpose terminal building was build at the airport area physically detached from main terminal. This "detention camp" 3 gives temporary accommodation to the refugees arriving by plane and prevents them from entering the territory of the nation. For enforced cosmopolitans with restricted legal rights, the comfort and airport services are reduced to the absolute minimum. Asylum seekers are not allowed to leave the building during their stay at the privately secured detention camp. During their stay they are entitled to medical and social assistance. Social workers try to animate their stay at the camp offering various indoor and outdoor activities. Asylum seekers are carefully placed in the rooms according to their cultural similarities or place of origins. Refugees are not allowed to cook in the building because cultural differences could cause problems. Therefore airport catering services supply the meals. Asylum seekers are representatives of middle and upper class of their countries of origins - those who can afford to pay for flight ticket. Accommodation at the camp is covered by German government for the time of airport procedure. In case of any delay of the stay after the court decision the airlines bringing potential asylum seekers to the country are obliged to cover further costs of stay.
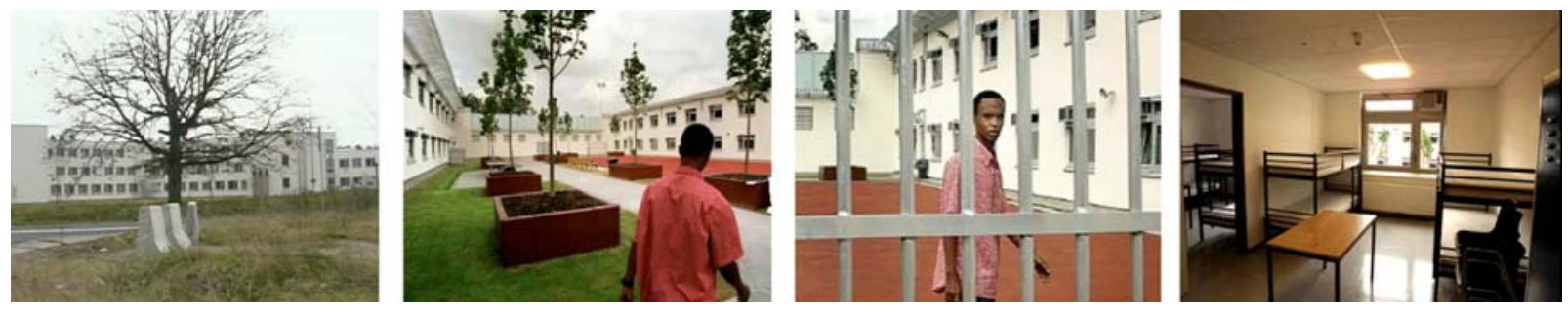

Figure 4: Rea lities of Detention Camp: Outside, Inside, Secured Courtya rd, Living Conditions (M. Codourey/Bettina Boknecht, 2005, Photo collage)

David Harvey (1999) wrote: "We have been experiencing, these at last two decades, an intense phase of time-space compression that has had a disorienting and disruptive impact upon politicaleconomic practices, the balance of class power, as well upon cultural and social life”. At the airport different legal orders create a manifold of sub-territories that are only accessible to a selected group of travellers. The territory of "frequent flyers" (lounges), separate HON/First Class Terminal of "kinetic elite," distant low-cost Airport Frankfurt - Hahn for price conscious tourists and as well business travellers, the secured territory of enforced cosmopolitans (detention camp) are all examples of emerging socio-spatial segregation at the airport.

\footnotetext{
2 The Airport Procedure is about establishing if refugees get the right to apply for asylum in Germany. It lasts 19 days. If a refugee gets sick in the camp and has to be brought to the hospital he still stays in transit. In case of acceptance as an asylum seeker, the refugee will be brought to an asylum camp and will be subject to the asylum procedure. In the case of non-acceptance as an asylum seeker, the refugee is subject to the deportation procedure. If the person does not have any travel documents, there are 2 possibilities: first a voluntary stay in the detention camp until papers are available. Or second, a move to the deportation jail and subject to proof procedure. If no passport is available after 9 months the refugee has to be moved to the asylum camp but without change of status. He is still not accepted for the asylum procedure and can be deported as soon as travel documents are available.

3 The detention camp is also a part of the airport transit area. The number of asylum seekers has rapidly decreased since the implementation of the "Airport Procedure" in 1993. Asylum seekers are not allowed to leave the building during their stay at the detention camp. They are not allowed to cook in the building because of cultural differences that could cause problems. Prepared meals are supplied by a catering service. Asylum seekers are carefully placed in the rooms according to their cultural similarities or place of origins. The airlines are responsible for bringing potential asylum seekers to the country, which are obliged to cover cost of accommodation in the camp.
} 
Codourey: Mobile Identities

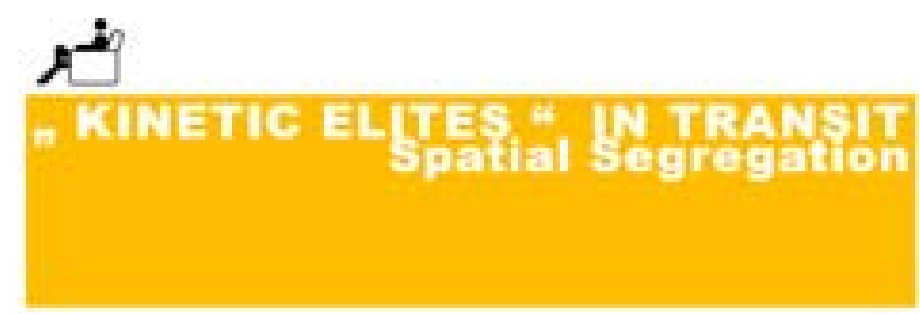

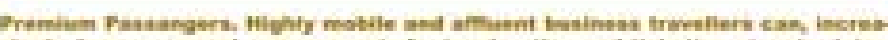

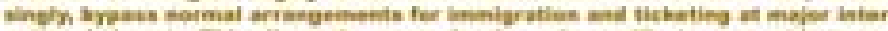

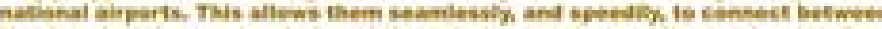

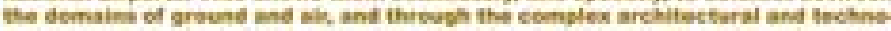

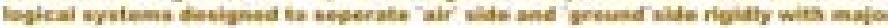

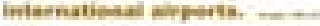

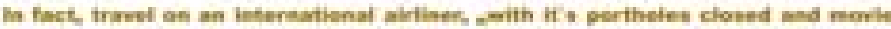

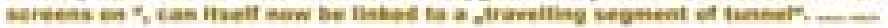

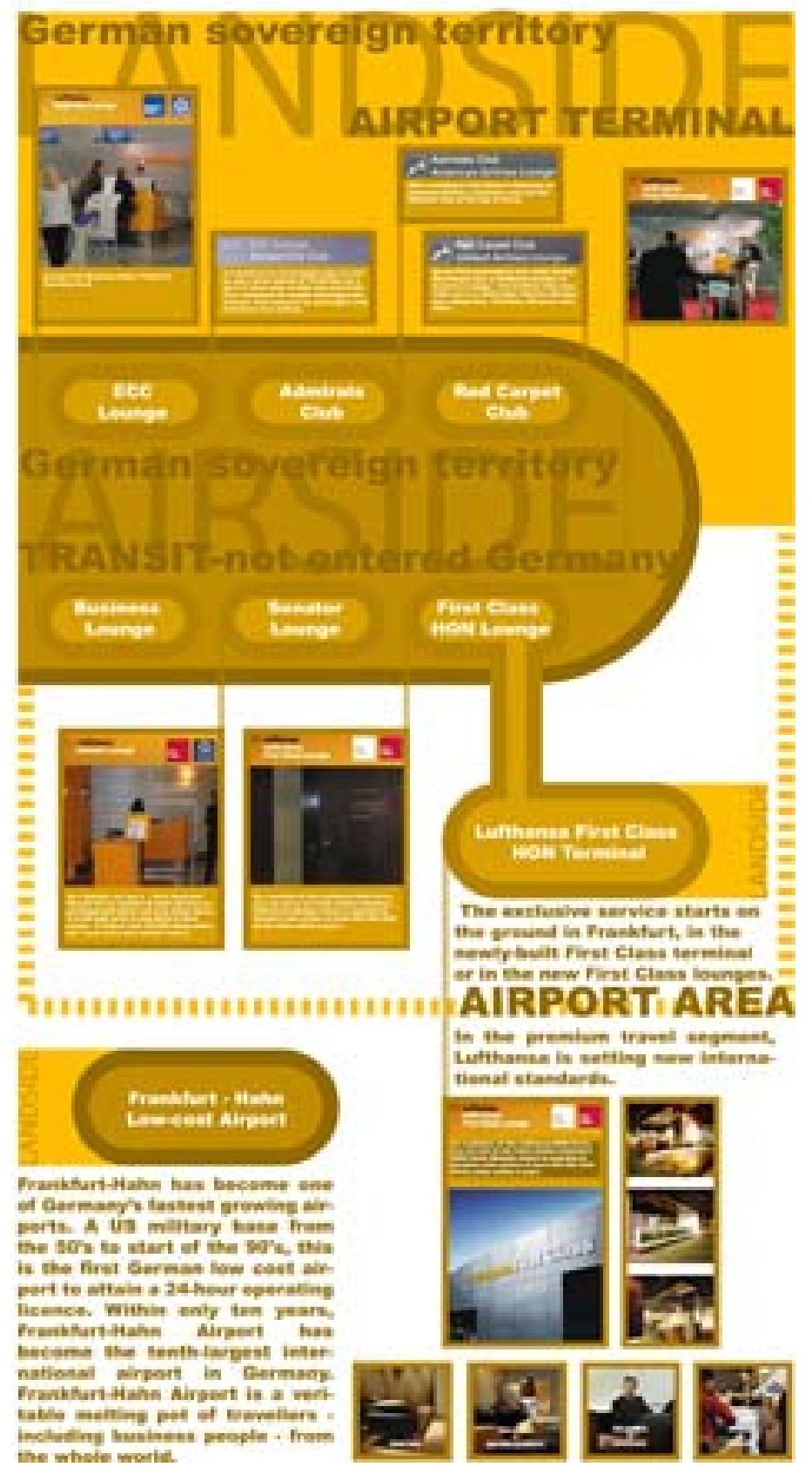

Figure 5: Airport Spatial Segregation; Sub-temitories of Kinetic Elites

(M. Codourey/B. Boknecht, 2005, Artistic Mapping) 


\section{Transit Condition of the Mobile Body; Locating the Border at the Frankfurt Aiport}

International airports are examples of emerging transnational spaces and can be understood as compressors of space and time. At the same time airports have become and important threshold controlling the flow of people in global economy and politics. For example, Frankfurt Airport is ranked as one of the world`s top five global nodes, one of the largest European hubs of intercontinental and international air traffic.

Frankfurt Airport not only facilitates global mass movement as efficiently as possible, but also is one of the most important access points to "Fortress Europe." This expression is often used to mean an attitude that wants to defend Europe from outside influences, especially cultural influences, through control and regulation of immigration procedures and asylum rights. Therefore, Frankfurt Airport was legally declared and extraterritorial zone, and it exists outside of territorial limits and German jurisdiction since 1993.

At Frankfurt International Airport the border condition turns into an exterritorial space itself, located within territorial boundaries of the nation state. It stands in contrast to the many state laws and regulation that apply to passengers; depending on nationality or travel status, regulate this zone. The International Air Agreement, Fundamental Rights (Asylum), the Geneva Refugee Convention, the Schengen Treaty and National Border Laws, Airport security measures, the Sky Marshals Agreement, Frequent Flyer Programs, Customs Law, Duty \& Tax Free Agreements or US Security Requirements are just a few examples of the growing list of the airport rules and regulations.

At the airport border the geopolitical concept of nation state and concept of global empire modify the relationship between geographical and political space. The access to both is regulated by very particular set of procedures and rules. The national border determines the geographical territory of a nation state and allows regulating an access to the country. At airports, the boundary of the nation is negotiated within an area inside the actual country. Moreover, the Frankfurt Airport border is not longer strictly national. Effective March 26, 1995 the Schengen Agreement has been implemented in Europe. The aim of this agreement is to remove immigration control for travel within the collective territories of the member states. This creates a border-less region known as the Schengen territory. The Schengen countries introduced a common visa policy for the whole area and agreed to establish effective controls at its external borders. Checks at the internal borders may be carried out for a limited period if public order or national security makes this necessary. On one side this space promises overcoming the violent legacies of the nation-state, while at the very same time undergoes a process of effective border fortification and cultural homogenization. Moreover, increasingly the border condition turns into a space itself: the airport's so-called transit area or air side is in fact a jurisdictional enclave inside the territorial boundaries of a nation ${ }^{4}$. Various laws, rules and agreements that apply to passengers, depending on nationality or travel status, regulate this zone.

\footnotetext{
4 Justine Lloyd points out that “The discursive basis of this border is clear in the history of the term 'air side.' The demarcation of a new form of border through this legal and administrative term - first used during the 1950s clearly describes that part of the global city which is not considered national territory for the purposes of immigration and customs control”
} 
Codourey: Mobile Identities

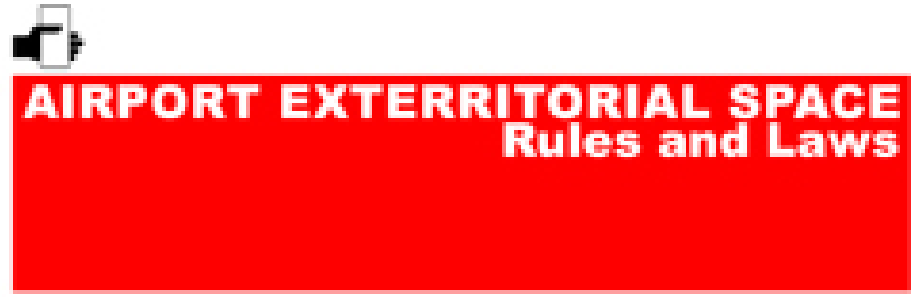

wairports eneresent highly rationalised, instrumentalised and deterritorialised realms.

Since 1933 Germany main international airpert, Frankfurt-Main, has been a isgally deciared detentios aened

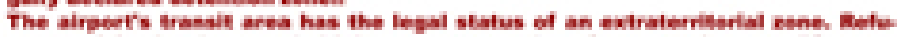
gees arriving by plane are held there to prevent them from entering upon -Oerman serritory", and thus beling able to flath meeve effectirely for their asylem and right He seay is Germang.
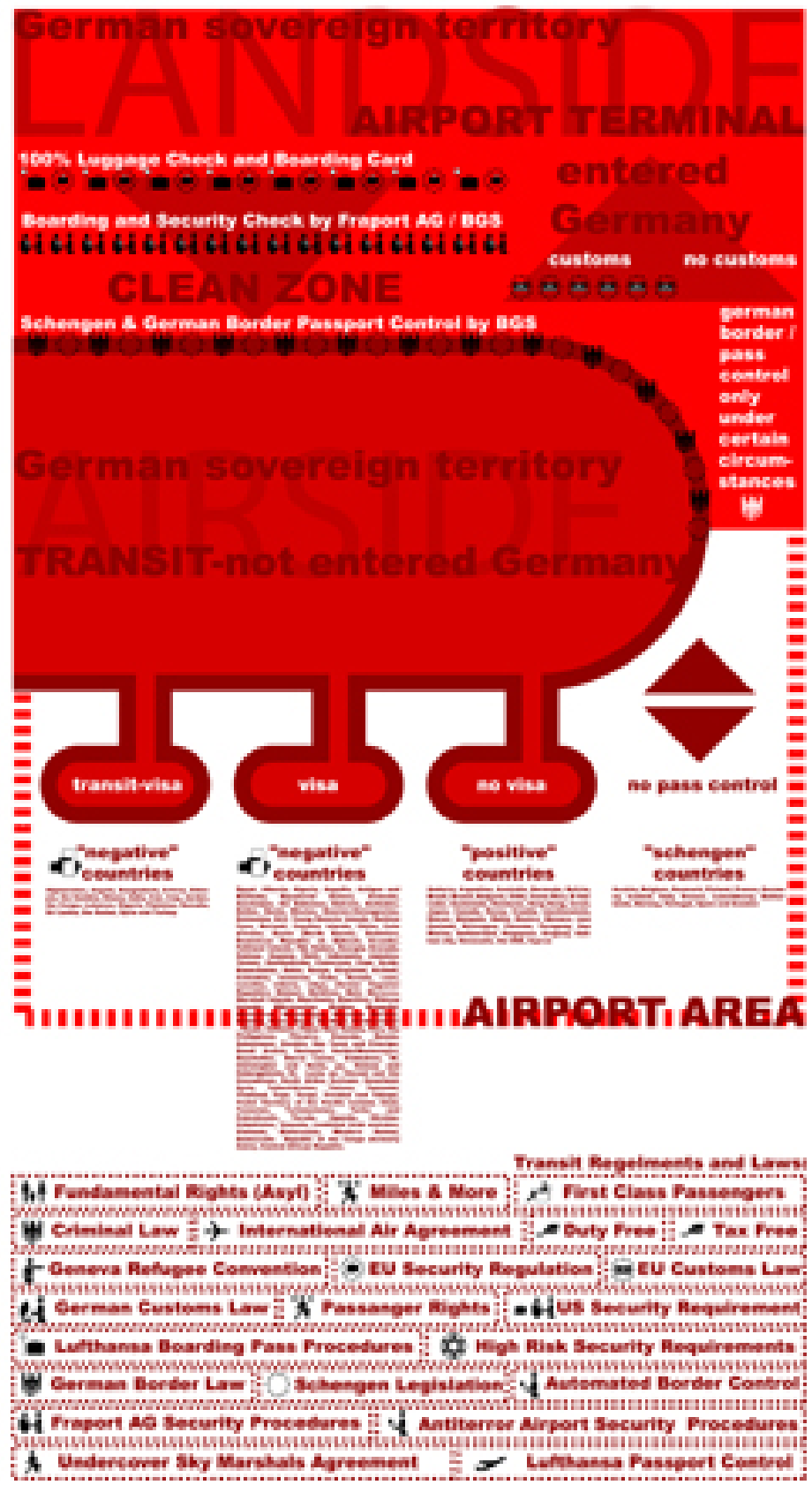

Surveillance \& Society 5(2)
Figure 6: "Fortress Europe" access privileges at the Frankfurt Airport

(M. Codourey/B. Boknecht, 2005, Artistic Mapping) 
What is more, in many cases the area of jurisdictional exclusion extends beyond the physical territory of airports. This makes it impossible to mark this artificial boundary at the footprint of airport. In fact it does not make any difference where the border is located. The checks can be activated at any time within airport transit zone depending on situation. For example, as long as the doors of the airplane are opened, the space of the airport is an extension of transit zone. Therefore German border control still has a power of enforcements. In the movement when the doors are closed international air law applies, though in theory as long as the plane is flying over German territory it is still subject to German law.

Another good example of the detachment between physical and social space practices is the implementation of the Airport Procedure. The Airport Procedure is about establishing if refugees get the right to apply for asylum in Germany before legally entering the country. During a nineteen-day procedure, asylum seekers are not allowed to leave the building during their stay at the airside of the airport, where they reside in a specially designated detention camp. In case of refusal to voluntarily stay in the detention camp, the refugee is transferred directly to a deportation jail and subject to so called Proof Procedure. In both cases, although the Asylum seekers are residing at the geographical territory of the country, they are not entitled to so called "entered Germany" status even if they have to be transported to the hospital or asylum camp, and are still subject to immediate deportation. Since the implementation of Airport Procedure the statistical number of asylum seekers has rapidly decreased because it is almost impossible to cross the German border in the legal sense. 


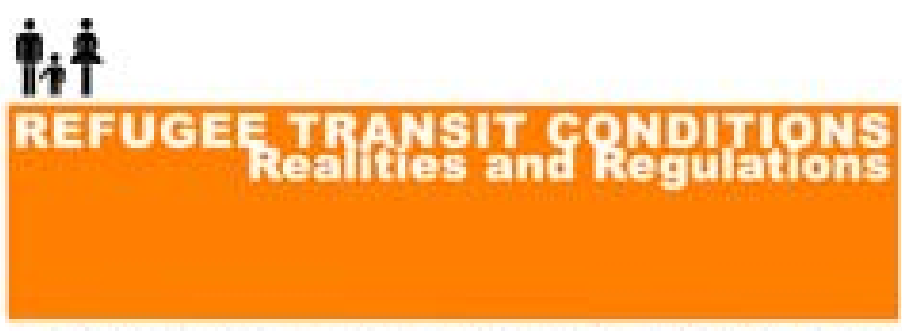

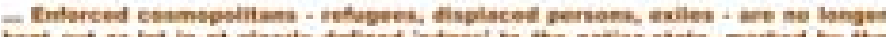

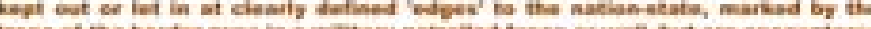

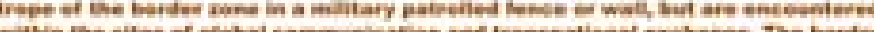

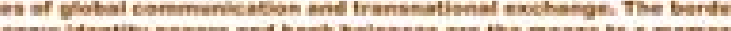

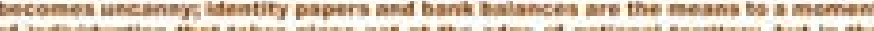

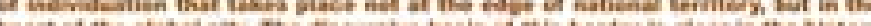

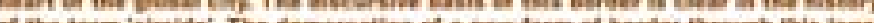

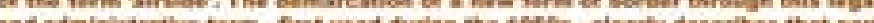

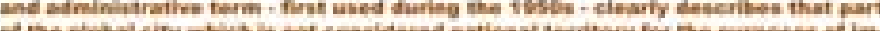

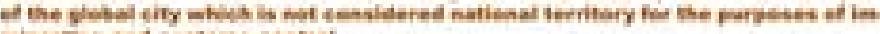
migrebien and evitems tentred .

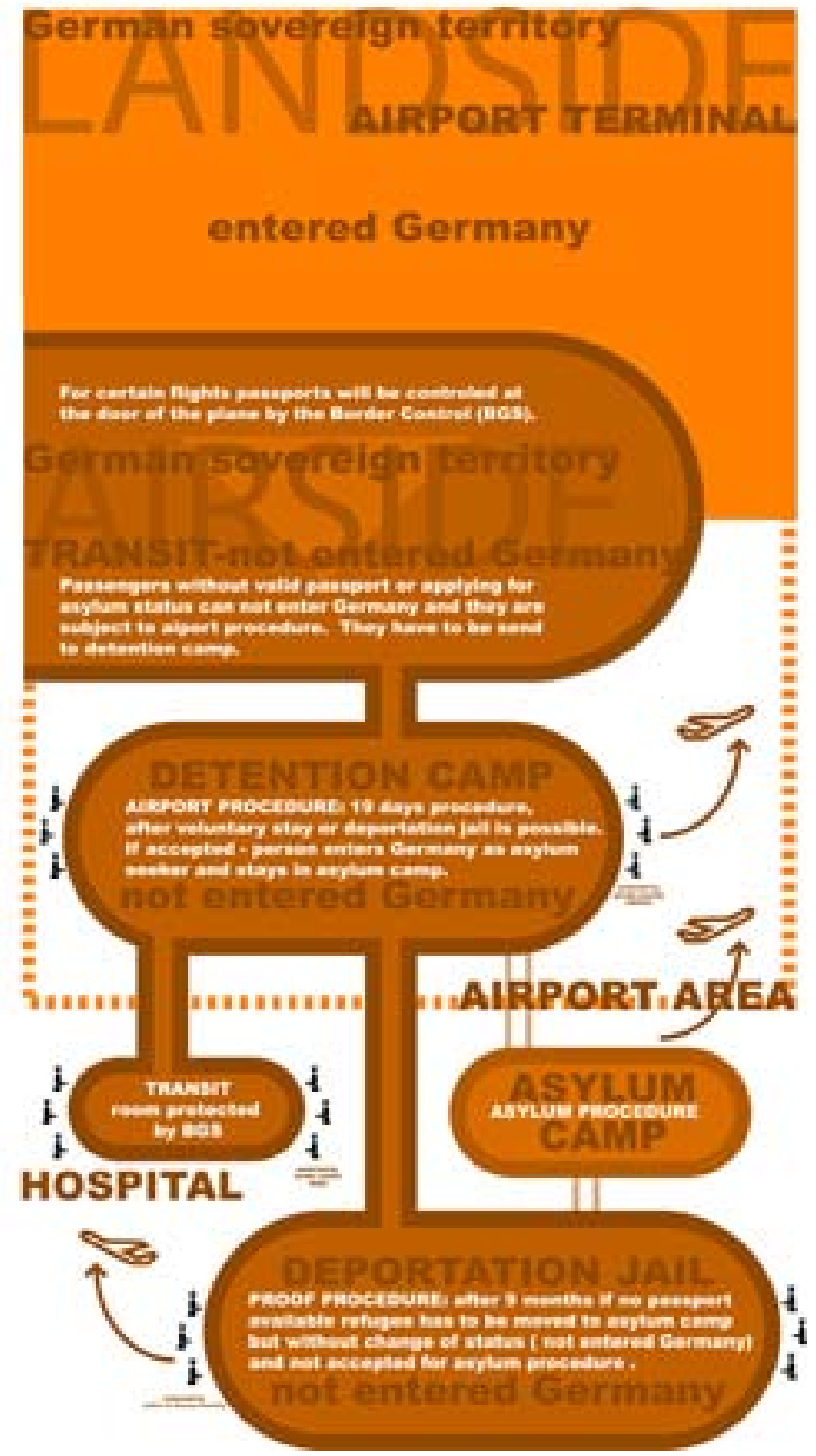

Surveillance \& Society $5(2)$
Codourey: Mobile Identities

Figure 7: Legal extension of exteritorial Zone outside aimort area for enforced cosmopolitans

(M. Codourey/B. Boknecht, 2005, Artistic Mapping) 
The airport border is not a simple line separating geographic regions or political divisions anymore. According to Balibar (1995) the borders are not disappearing, they are intensifying and being both "multiplied and reduced in their localization and their function, thinned and doubled, even becoming zones, regions and countries where people are forced to reside and live". Nowadays, rather than geographical boundary of the state, the airport borders are a transit condition of the mobile body.

The rules and regulations of Transit Zone apply to people as well as to airfreight. In the case of goods, extended zones excluded from national jurisdiction, support the "just-in-time" economies of free trade zones. Within the transnational state, the flow of goods within global markets is free of borders or boundaries. It is efficient and it is furthered through the individual purchase of goods in duty and tax-free stores located throughout its transit zones.

\section{Technology of Space and Body in Transit}

The legally declared extraterritorial zone of the airport hub becomes an important threshold controlling access to the new Europe and regulating the flow of people and goods in a free market economy. This space in-between, outside of territorial limits of the nation, is in fact and abstract space created by a bureaucratic system of inclusion and exclusion within transnational states. Transit zone at airports emerge because of a complex set of factors: border crossing as well as today's security and safety regulations. The innumerable thresholds to the transit zones are points of congestion that are governed by an imperfect system of identification. Nowadays, the airport constitutes a space with a series of contractual declarations.

The complexity of the procedure for controlling mobile subjects is rapidly increasing. Nowadays departure means going through check-in, security control of luggage, body and boarding card as well border and customs check if necessary. In some cases the border and security control may even be repeated before entering the plane.

All of these safety, security and national boundaries are controlled by different authorities. Airlines are responsible for proper check-in of passengers and control of all travel documents and required visas. Security and border control are duties of national guards and control of goods are handled by customs. Moreover, personnel, visitors, travellers, luggage, ticket controls are performed by airport operators or even outsourced to external security sub-contractors. The points of control are not only about controlling, granting or refusing access but the issue of which controlling instances have responsibility to perform a particular check.

In the case of departure and arrivals within Schengen countries, border checks are done only occasionally and custom controls are not required. The newest security and safety regulation require an absolute spatial segregation between passengers flying within and outside Schengen area. Therefore the airside zone for flights within Schengen countries does not have an extraterritorial status and is described as Clean Zone. In the age of endless security procedures and hyper-surveillance mixed with neo-liberal politic "the times of famous architecture of glass and steel are over. The only thing that counts is a footprint," as Fraport AG press speaker noted. 


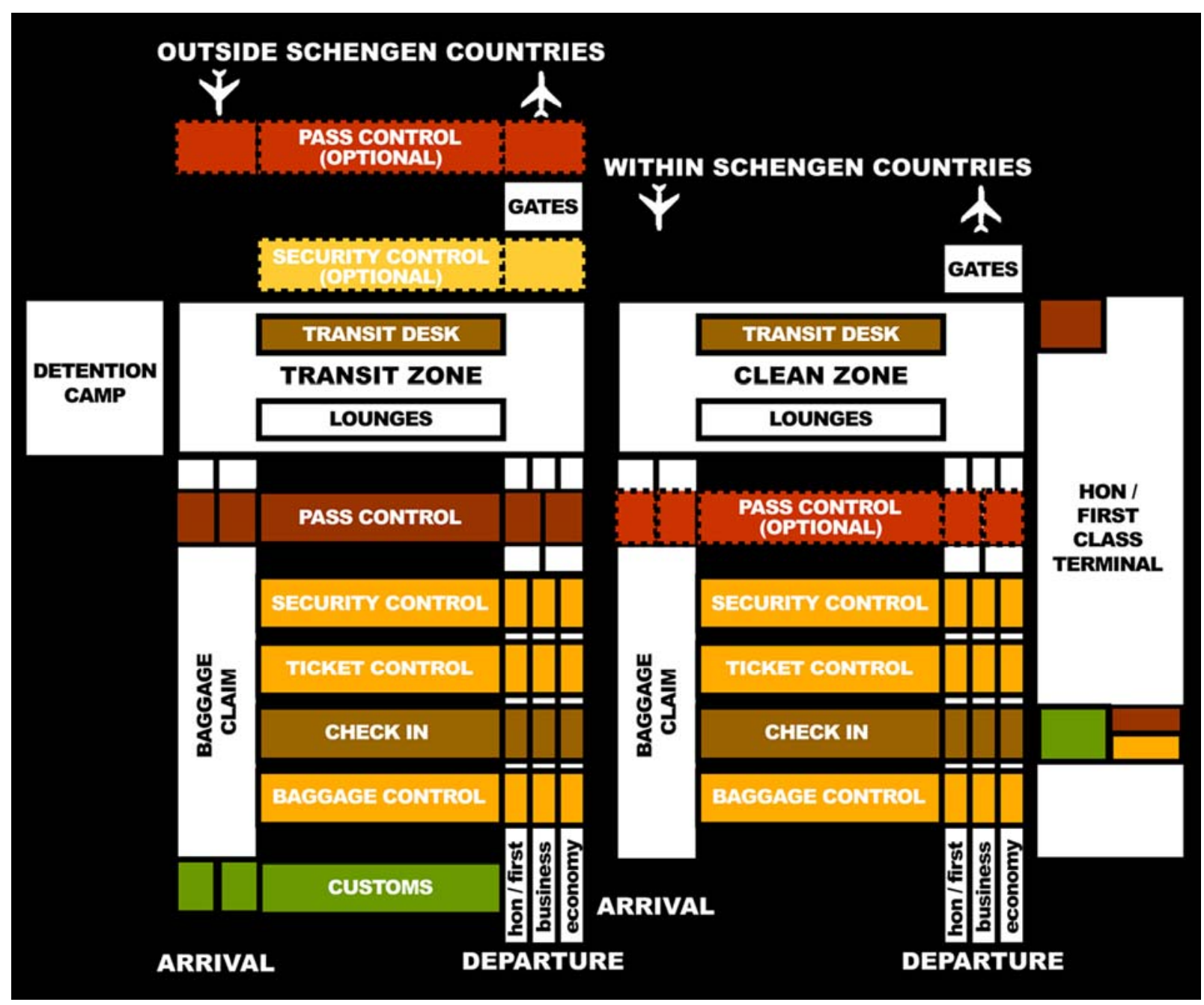

Figure 8: "Tunnelling Effect" at a irport thresholds (M. Codourey, 2005, Diagram)

Travellers move through airport safety and security thresholds at different speeds. The economy class travellers must take into account longer check-in procedures than privileged business and first class travellers. Paul Virilio (1991) observed that: "Highly mobile and affluent business travellers can, increasingly, bypass normal arrangement for immigration and ticketing at major international airports. This allows them seamlessly, and speedily, to connect between the domains of ground and air, and through the complex architectural and technological systems designed to separate `air` side and `ground side rigidly with major international airports.” 

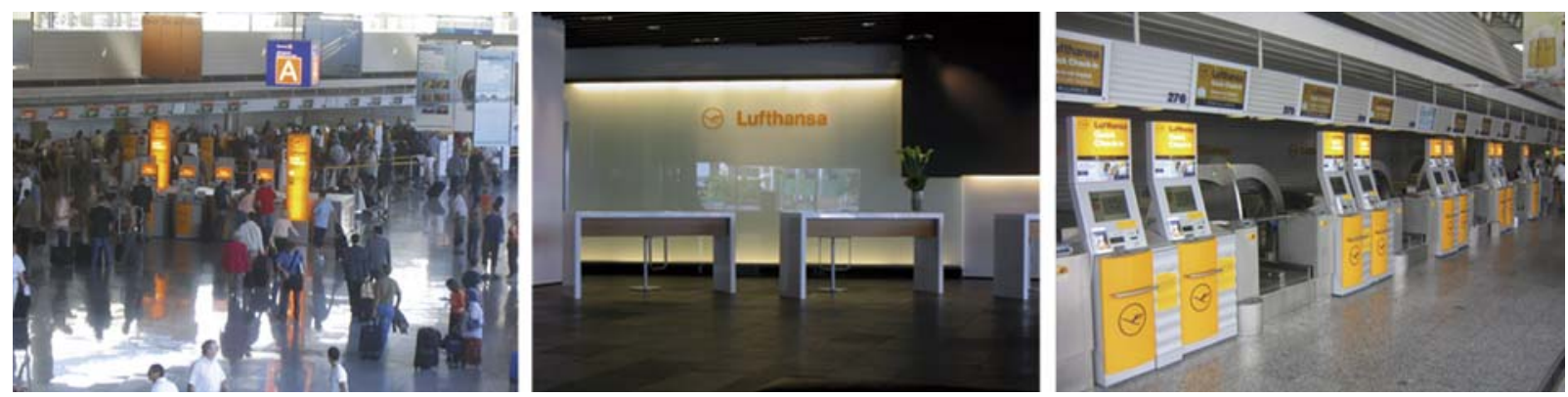

Figure 9: Check-in points for economy, $\mathrm{HON}$ /first class and quick check-in teminal (M. Codourey, 2005, Photo collage)

In point-to-point airport traffic management, technology plays an increasingly important role. Metal detectors, X-ray machines, quick check-in and other facilities are already a vital part of transnational spaces of control and security. The discourse of border protection demonstrates that by invoking second-order metaphors of virus detection in the national body of data, the nation state increasingly must discriminate between real and fake identities, purely economic and purely political migrants. In order to guarantee the highest degree of security possible, recently airports have been using the latest technology in automated border control. It replaces face-toface (F2F) interaction between the controlled and those who control. The newest technology is based on biometrics and allows fast and convenient self-service border checks and grants entitled travelers unrestricted freedom of movement ${ }^{5}$. This method also allows authorities to be more efficient and accurate when identifying people at airport border crossings.
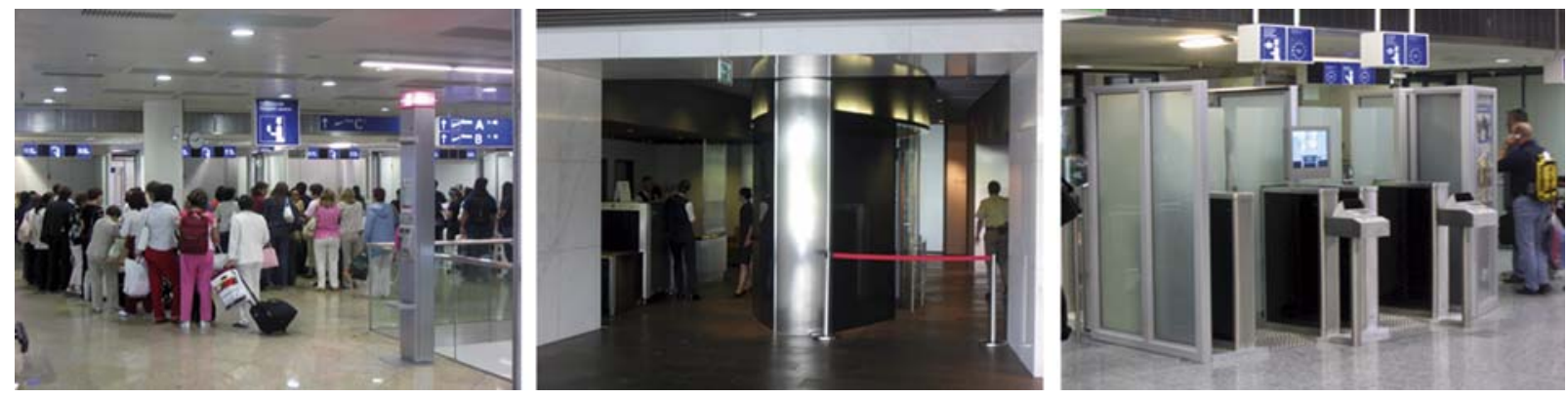

Figure 10: Border crossing for economy, HON/first class and " smart border" (M. Corduroy, 2005, Photo collage)

The biometric system of authentication ties access codes to the bodies of travellers. Mobile individuals no longer have to be identified as a whole. The pattern match, the algorithmic logic of a database, replaces characteristics of the individual in a biometric system of control, inclusion and exclusion. Because they measure and statistically analyze the body as biological data,

\footnotetext{
5 "Fast and convenient - in the future you can handle border checks yourself. If you don't feel like waiting in line at the border control point, you can use the new automatic border control lanes at Frankfurt Airport. Until now passengers on non-Schengen flights were checked by border control officers each time they entered Germany. This manual check often included long waiting lines... Participation is voluntary, however, only citizens from the EU/EEC countries and Switzerland entitled to unrestricted freedom of movement who are 18 years or older and hold a machine-readable passport may participate.” (BGS flyer. Automated Border Control. Do you want to participate?)
} 
biometrics $^{6}$ is the perfect match for permeable borders, ensuring the verification of the uniqueness of every body ${ }^{7}$.

Biometrics is another way in which the flows of life are increasingly captured and reassembled through "stop-go" technologies that don't work through signification but instantiate or straight into informational sequences.

Increasingly, the conventional system of control, inclusion and exclusion based on Face-to-Face interaction between the controlling and the controlled, will be replaced by the algorithmic logic of databases. The pattern match ensures the verification of the unique of the body and allows patterning of exits and entries across thresholds more flexible rather than boundaries impermeable. For example, soon anyone from a visa-waiver country wanting to travel to the U.S. must have a biometric encrypted in their travel documents. This will not only speed processing at the border, but it also works in compliance with so-called US-VISIT entry-exit system, based on the concept of the inventory tracking system found in a warehouse. In this system of relevance the body must be captured, coded and scanned first. Therefore, mobile individuals are increasingly integrated into a collective electronic database; a collection of data arranged for easy and speedy search and retrieval. Transnational spaces of airports continue to face different patterns of mobility that are also concerned to the biometric pattern match. In the nearest future, anyone who resists submitting his or her body pattern into a global network of tracking and control will simply not gain access to transit zone.

Today, the airport is more than just a mixture of complex infrastructures and the emergence of city-like functions. It has become a translational state of mobility. Nowadays airports are a manifestation of technology of abstract procedures of transition, inclusion and exclusion and emergent patterns of socio-spatial mobility in the global network.

\footnotetext{
${ }^{6}$ Biometrics is the science and technology of authentication by measuring the person's physiological or behavioral features. The term is derived from the Greek words "bios" for life and "metron" for measure. In a typical IT biometric system, a person registers with the system when one or more of his physiological characteristics are obtained, processed by a numerical algorithm, and entered into a database. Ideally, when he logs in, all of his features technology, "match $100 \%$; then when someone else tries to log in, she does not fully match, so the system will not allow her to log in. Current technologies have widely varying Equal Error Rates - as low as 60\% and as high as $99.9 \%$.”

7 The objective of the project is to create a database of mobile identities that is open to everyone, and draw attention to issues pertaining to the classification of mobile subjects. The project interface allows for the scanning of photos of eyes into a databank. Persons participating in the project were asked to fill out a " 5 minute Travel Form.” The travel form asks for information on, for example, travellers' mobility patterns, their perception of the airport space and their particular experience with or emotions about airport border controls. Installation: Data Records of Mobile Identities, http://www.mobile-identities.info
} 


\section{DATA RECORDof MOBILE IDENTITIES}

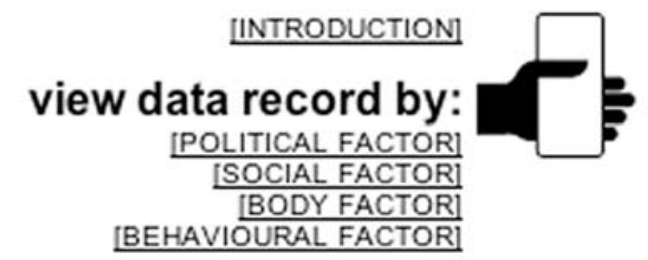

[eye photo upload]
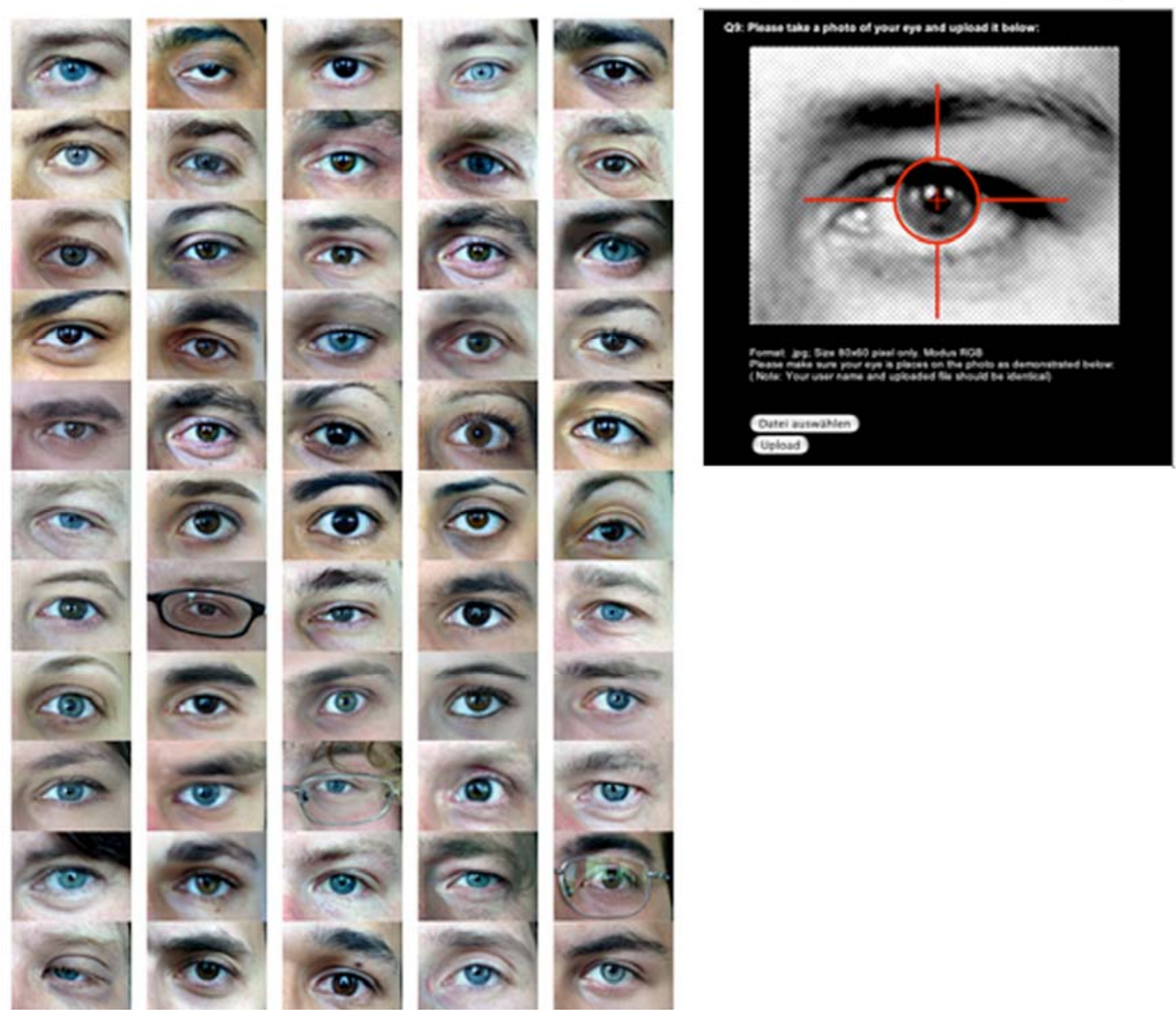

Figure 11: Uniqueness of Everybody in Insta llation: Data Record of Mobile Identities. http://www. mobile-identities.info (M. Codourey/B. Boknecht, 2005, Installation) 


\section{References}

Albrow, M. (1997) 'Travelling Beyond Local Cultures. Socioscapes in a global city,' in J. Eade (ed.) Living the Global City: Globalization as Local Process. New York: Routledge, 37-55.

Balibar, E. (1995) ‘Ambiguous Universality,’ Differences 7 (1): 48-74

Gottdeiner, M. (2001) Life in the Air: The New Culture of Air Travel. New York: Rowman \& Littlefield.

Harvey, D. (1990) The Condition of Post-modernity. Oxford: Blackwell.

Sloterdijk, P. (1988) Critique of Cynical Reason. London: Verso

Lloyd, J. (2002) 'Departing Sovereignty,' Borderlands 1(2): no page numbers.

http://www.borderlandsejournal.adelaide.edu.au/vol1no2_2002/lloyd_departing.html

Virilio, P. (1991) Aesthetics of Disappearance. New York: Semiotext(e).

\section{Related Projects:}

1. [Mapping Sozio-spatial Mobilities] (2005-06, Field Research, Spatial Analysis and Mapping)

2. [Airport Transit Condition] (2006, video, 17.min), view trailer or contact inom@inom.info for a copy.

3. [Data Record of Mobile Identities], (2005, Installation) Available online: http://www.mobile-identities.info 